\title{
Role of Caspase-9 Gene Ex5+32 G>A (rs1052576) Variant in Susceptibility to Primary Brain Tumors
}

\author{
SELCUK OZDOGAN ${ }^{1}$, ALI KAFADAR ${ }^{2}$, SEDA GULEC YILMAZ $^{3}$, \\ OZLEM TIMIRCI-KAHRAMAN ${ }^{4}$, UZAY GORMUS ${ }^{5}$ and TURGAY ISBIR ${ }^{6}$ \\ ${ }^{1}$ Department of Neurosurgery, Dr. Lutfi Kirdar Kartal Training and Research Hospital, Istanbul, Turkey; \\ ${ }^{2}$ Department of Neurosurgery, Cerrahpaşa Medical Faculty, Istanbul University, Istanbul, Turkey; \\ ${ }^{3}$ Department of Molecular Medicine, Institute of Health Sciences and \\ ${ }^{4}$ Department of Molecular Medicine, Aziz Sancar Institute of Experimental Medicine, \\ Istanbul University, Istanbul, Turkey; \\ ${ }^{5}$ Department of Molecular Biology and Genetics, Faculty of Medicine, Istinye University, Istanbul, Turkey; \\ ${ }^{6}$ Department of Medical Biology, Faculty of Medicine, Yeditepe University, Istanbul, Turkey
}

\begin{abstract}
Background/Aim: This study is the first to evaluate the relationship of caspase-9 (CASP-9) gene polymorphism with the risk for primary brain tumor development. Materials and Methods: The study group included 43 glioma and 27 meningioma patients and 76 healthy individuals. CASP-9 gene Ex5+32 G>A (rs1052576) polymorphism was analyzed by real-time polymerase chain reaction (RT-PCR). Results: Individuals with the CASP-9 GG genotype had significantly decreased risk of developing a glioma brain tumor $(p=0.024)$. Additionally, the $G A$ genotype was significantly lower in patients with glioma than the control group $(p=0.019)$. A significantly decreased risk of developing glioma was found in the A allele carrier group ( $p=0.024)$. However, there was no statistically significant relationship between CASP-9 polymorphism and brain meningioma $(p=0.493)$. Conclusion: CASP-9 (rs1052576) mutant A allele seems to be a protective factor for glioma brain tumor. Future studies with a larger sample size will clarify the possible roles of CASP-9 gene in the etiology and progression of primary brain tumors.
\end{abstract}

Primary brain tumors are multifactorial diseases with poor survival (1). The most common types of adult primary brain tumors are gliomas and meningiomas (2). Gliomas account for almost $80 \%$ of primary brain tumors and have poor

Correspondence to: Professor Turgay Isbir, Chairman, Department of Medical Biology, Faculty of Medicine, Yeditepe University, İnönü Cad. 26 Ağustos Yerleşkesi, 34755 Kayışdağı-Ataşehir, Istanbul- Turkey. Tel/Fax: +90 5332823726/+90 2165780000/1263, e-mail: turgay.isbir@yeditepe.edu.tr, tisbir@superonline.com

Key Words: Caspase-9, glioma, meningioma, polymorphism. prognosis despite the use of multimodality treatments, total surgical resections and adjuvant therapies. Gliomas are locally invasive, rarely metastasizing tumors $(3,4)$. Meningiomas are usually slow-growing benign tumors arising from the meninges (5). Many environmental and lifesytle factors, including smoking, diet, alcohol, exposure to electromagnetic fields, ionizing radiation and several occupations are thought to be associated with increased primary brain tumors risk $(6,7)$. Researches in molecular medicine have revealed that malignant behavior of primary brain tumors are based on genetic and biochemical abnormalities (8-10). The molecules/pathways identified in these studies could be potential targets for therapeutics.

Abnormal cell growth and proliferation in cancer could be the result of defects in apoptosis $(11,12)$. Caspases are cysteine proteases which are responsible for diverse cellular functions and apoptosis. There are two major apoptotic pathways known as intrinsic and extrinsic pathways (13). 03-8 and -9 have been proved to be the main caspases in those pathways (14). There are two types of caspases: apoptotic caspases and inflammatory caspases (caspase-1, -4, -5, and -11). Caspase-2, -8, -9, -10, and -12 are known as initiators and caspase- $3,-4,-7$, and -12 as effectors directly activating the downstream of the initiator caspases, or indirectly activating due to a secondary messenger mechanism, and cleaving certain cellular substrates to cause demolition of the cells $(12,15)$.

Caspase- 9 is a cysteine peptidase encoded by the CASP-9 gene located on chromosome 1p36.1 (16-18). Several candidate and novel polymorphisms in the CASP-9 gene have been recently reported in the databases (19). Nevertheless, the functional effects of those polymorphisms have not been clarified, and it has been assumed that some of the variants can influence CASP-9 expression or activity, thus modulating susceptibility to cancer. 
Therefore, in this study, we conducted a case-control study in a Turkish population, and investigated the association between CASP-9 Ex5+32 G>A (rs 1052576) polymorphism and development of primary brain tumors. To our knowledge, this is the first analysis of the CASP-9 gene variant in glioma and meningioma patients.

\section{Materials and Methods}

Study population. The hospital-based prospective case-control study included 70 primary brain tumors (43 glioma and 27 meningioma). All partipiciants were selected in the Neurosurgery Departments of Kartal Training and Research Hospital and Cerrahpasa University, Istanbul, Turkey. Pathological investigations of brain tumors were determined according to the World Health Organization Classification of Tumors (20). A total of 76 healthy subjects were selected for the control group. The clinical data of the patients were recorded and followed-up prospectively. Demographic characteristics of patients and controls were obtained from medical records of the subjects.

Genetic analysis. After obtaining informed consent from all individulas, peripheral blood samples were collected into EDTA-tubes. DNA extraction was performed by iPrep Purification Instrument (Invitrogen, Life Technologies, Carlsbad, California, USA) by using $350 \mu 1$ of peripheral blood and Invitrogen iPrep PureLink gDNA blood isolation kit (Invitrogen, Life Technologies, Carlsbad, California, USA). Isolated DNA samples were measured with NanoDrop 2000 (Thermoscientific, Waltham, Massachusetts, USA), 1.7-1.9 optical density range were taken for genotyping and final concentrations of samples diluted to approximately $100 \mathrm{ng} / \mu \mathrm{l}$. Genotyping for CASP 9 gene rs 1052576 polymorphism was performed by Applied Biosystems 7500 Fast Real- Time PCR instrument (Applied Biosystems, Foster City, CA, USA) by using TaqMan Genotyping Assay, TaqMan Genotyping Master Mix (TaqMan Reagents, Applied Biosystems, Foster City, CA, USA) and $100 \mathrm{ng}$ of sample DNA. Reaction mixture and conditions were used as recommended by manifacturer. The reaction conditions were $10 \mathrm{~min}$ at $95^{\circ} \mathrm{C}$ hold stage and 40 cycles of $15 \mathrm{sec}$ at $92^{\circ} \mathrm{C}$ denaturation and $60 \mathrm{sec}$ at $60^{\circ} \mathrm{C}$ annealing/extention. Allelic discrimination of samples by collecting and interpreting flourescent signals of hybridization probes by software of 7500 Fast Real- Time PCR instrument.

Statistical analysis. Statistical analysis were performed using SPSS Ver. 23 software (SPSS Inc, Chicago, IL, USA). The significant differences between groups were examined by Student's $t$-test and demographic informations were compared by Chi square and Fisher's exact tests. $p<0.05$ was denoted as statistically significant.

\section{Results}

The analysis included 43 glioma, 27 meningioma patients and 76 controls. The mean age of the patients with glioma, meningioma and healthy controls were $46.73 \pm 10.87$, $52.00 \pm 11.61$ and $51.44 \pm 17.61$ years, respectively. No significant differences were found between primary brain tumor and control groups in terms of median age $(p=0.124$; $p=0.910)$. The frequency of gender was considerably different for the patients and controls (51.4\% male, $48.6 \%$ female for patients; $76 \%$ male, $24 \%$ female for controls). There were significant differences with regards to gender in the study group $(p=0.002)$.

The allele and genotype frequencies for CASP-9 Ex $5+32$ $\mathrm{G}>\mathrm{A}$ (rs 1052576) polymorphism in patients with glioma and controls are shown in Table I. CASP-9 Ex 5+32 G>A genotype frequencies between glioma patients and controls were statistically significant $\left(\chi^{2}=6.305 ; p=0.043\right)$. As shown in Table I, the frequency of the GG and GA genotype was significantly higher in the control group than the glioma patients $\left(\chi^{2}=6.305, p=0.024 ; \mathrm{OR}=0.363,95 \% \mathrm{CI}=0.148-0.890\right.$ and $\left.\chi^{2}=5.511 ; p=0.019 ; \mathrm{OR}=0.655,95 \% \mathrm{CI}=0.466-0.922\right)$ Although there was no significant difference in $\mathrm{G}$ allele frequency between the study groups $\left(\chi^{2}=0.106 ; p=0.744\right)$, the frequency of A allele was statistically significantly higher in the glioma group $\left(\chi^{2}=5.511 ; p=0.024\right)$. Our results indicated that carrying $\mathrm{A}$ allele decreased the glioma risk 0.7 fold $(\mathrm{OR}=0.754,95 \% \mathrm{CI}=0.599-0.948)$.

The allele and genotype frequencies of CASP-9 Ex $5+32$ $\mathrm{G}>\mathrm{A}$ (rs1052576) in patients with meningioma and controls are given in Table II. GG, GA, and AA genotypes of the patients with meningioma were $25.9 \%, 51.9 \%$ and $22.2 \%$, respectively, and the control subjects were $38.7 \%, 42.7 \%$, and $18.7 \%$, respectively. The observed genotype frequencies of CASP-9 Ex5+32 G>A (rs1052576) in patients with meningioma and control groups were in agreement with the Hardy-Weinberg equilibrium $\left(\chi^{2}=1.412 ; p=0.493\right)$. In addition, there was no significant difference in CASP-9 Ex $5+32 \mathrm{G}>\mathrm{A}$ alleles between the meningioma and control groups $(p>0.05)$.

\section{Discussion}

Understanding the molecular mechanisms underlining primary brain tumors assist to cover the gaps in apprehending the pathogenesis of this tumor and potentially provide better prognosis. Several studies have established that some genetic variants affect the expression or the activities of various enzymes and are therefore associated with the cancer risk $(21,22)$.

Apoptosis is a physiological process regulating programmed cell death (23). Defects in this mechanism can lead to abnormal cell growth and proliferation in cancer development (24). Caspase-9 is a member of the caspases (cysteine-aspartic protease) family involved in the apoptotic process (25). Altough some studies have investigated the association of CASP-9 gene SNPs with cancer risk, results are not clear enough.

The CASP-9 (Ex5+32 G>A, rs1052576) polymorphism encodes for a glutamine to arginine amino acid change at codon 221 of the protein (26). The Q221R variant might induce conformational changes in the molecule, and because of that may have functional significance $(27,28)$. However few studies have evaluated the association between this polymorphism and cancer risk. Hosgood et al. examined the 
Table I. CASP-9 Ex5+32 G>A (rs1052576) genotype genotype and allelle frequencies in patients with glioma and the control group.

\begin{tabular}{|c|c|c|c|c|c|}
\hline & $\begin{array}{c}\text { Glioma } \\
\mathrm{n}(\%)\end{array}$ & $\begin{array}{c}\text { Control } \\
\mathrm{n}(\%)\end{array}$ & $p$-Value & OR & $95 \% \mathrm{CI}$ \\
\hline \multicolumn{6}{|c|}{ CASP-9 (rs1052576) genotype } \\
\hline GG & $8(18.6 \%)$ & $29(38.7 \%)$ & $0.024 *$ & 0.363 & $0.148-0.890$ \\
\hline GA & $28(65.1 \%)$ & $32(42.7 \%)$ & $0.019 *$ & 0.655 & $0.466-0.922$ \\
\hline AA & $7(16.3 \%)$ & $14(18.7 \%)$ & 0.744 & 0.847 & $0.313-2.295$ \\
\hline \multicolumn{6}{|c|}{ CASP-9 (rs1052576) allele } \\
\hline G & $44(51.1 \%)$ & $90(60.0 \%)$ & 0.744 & 0.971 & $0.819-1.152$ \\
\hline A & $42(48.9 \%)$ & $60(40.0 \%)$ & $0.024 *$ & 0.754 & $0.599-0.948$ \\
\hline
\end{tabular}

$\mathrm{N}$ : Number of individuals; OR: odds ratio; CI: confidence interval. *p-Values less than 0.05 denoted statistical significance.

Table II. CASP-9 Ex5+32 G>A (rs1052576) genotype and allelle frequencies in patients with meningioma and the control group.

\begin{tabular}{|c|c|c|c|c|c|}
\hline & $\begin{array}{c}\text { Meningioma } \\
\mathrm{n}(\%)\end{array}$ & $\begin{array}{c}\text { Control } \\
\mathrm{n}(\%)\end{array}$ & $\mathrm{p}$-Value & OR & $95 \% \mathrm{CI}$ \\
\hline \multicolumn{6}{|c|}{ CASP-9 (rs 1052576) genotype } \\
\hline GG & $7(25.9 \%)$ & $29(38.7 \%)$ & 0.235 & 1.491 & $0.742-2.999$ \\
\hline GA & $14(51.9 \%)$ & $32(42.7 \%)$ & 0.411 & 0.823 & $0.526-1.288$ \\
\hline AA & $6(22.2 \%)$ & $14(18.7 \%)$ & 0.690 & 0.840 & $0.359-1.964$ \\
\hline \multicolumn{6}{|c|}{ CASP-9 (rs1052576) allele } \\
\hline $\mathrm{G}$ & $28(43.7 \%)$ & $90(60.0 \%)$ & 0.690 & 0.803 & $0.274-2.359$ \\
\hline A & $36(56.3 \%)$ & $60(40.0 \%)$ & 0.235 & 1.801 & $0.677-4.791$ \\
\hline
\end{tabular}

n: Number of individuals; OR: odds ratio; CI: confidence interval. *p-Values less than 0.05 denoted statistical significance.

association of CASP-9 Ex5+32 G>A polymorphism with multiple myeloma. They found significantly higher frequencies of AA and AG genotypes in the control group than in patients with multiple myeloma (29). Similarly, Lan et al. showed that CASP-9 rs1052576 polymorphism was significantly associated with decreased risk for non-odgkin lymphoma (30). Zhang et al. investigated 2733 neoplasmic cases and 3352 healthy controls concerning CASP-9 Ex5+32 $\mathrm{G}>\mathrm{A}$ polymorphism. They suggested that the rs1052576 A allele might decrease the risk of cancer (31). Yan et al. performed a meta-analysis of 1668 cancer cases and 2294 healthy controls. A allele of Ex $5+32 \mathrm{G}>\mathrm{A}$ in the CASP-9 gene was found to have protective factor for cancer risk in Chinese, American and Asian populations, but not in the Caucasian population (32). Conformably, in another meta-analysis, Xu et al. showed that the A allele of rs1052576 might be a protective factor for cancer, especially for Asians (33). Previous studies ensured evidence that this SNP may play important roles in the prognosis of cancer in various populations, however is currently unknown for the Turkish population. Additionally, to the best of our knowledge, no published study previously investigated the association between this variant in CASP-9 gene and the risk of developing primary brain tumors.

Therefore, the present study is the first to evaluate the relevance of CASP-9 Ex5+32 G>A functional polymorphism in the risk of glioma and meningioma. Similar to other studies, our results demonstrated that the CASP-9 rs1052576 A allele was at a decreased risk for glioma development, but no statistical significance for interaction between $C A S P-9$ gene variant and meningioma was detected. Since genetic polymorphisms often show ethnic differences, further functional studies are needed to evaluate genotype and phenotype correlation in large cohorts of various ethnicities.

\section{Conflicts of Interest}

The Authors declare that they have no financial disclosures or conflicts of interest.

\section{References}

1 Bondy ML, Scheurer ME, Malmer B, Barnholtz-Sloanet Jill, Davis FG, Il'yasova Dora, Kruchko C, McCarthy BJ, Rajaraman P, Schwartzbaum JA, Sadetzki S, Schlehofer B, Tihan T, Wiemels JL, Wrensch $\mathrm{M}$ and Buffler PA: Brain tumor epidemiology: consensus from the Brain Tumor Epidemiology Consortium. Cancer 113(Suppl 7): 1953-1968, 2008.

2 Fisher JL, Schwartzbaum JA, Wrensch M and Wiemels JL: Epidemiology of brain tumors. Neurol Clin 25(4): 867-890, 2007. 
3 Goodenberger ML and Jenkins RB: Genetics of adult glioma. Cancer Genet 205: 613-621, 2012.

4 Louis DN, Ohgaki H, Wiestler OD, Cavenee WK, Burger PC, Jouvet A, Scheithauer BW and Kleihues P: The 2007 WHO classification of tumours of the central nervous system. Acta Neuropathol 114: 97-109, 2007.

5 Marosi C, Hassler M, Roessler K, Reni M, Santa M, Mazza E and Vecht C: Meningioma. Crit Rev Oncol Hematol 67(2): 153171, 2008.

6 Goodenberger ML and Jenkins RB: Genetics of adult glioma. Cancer Genet 205: 613-621, 2012.

7 Ohgaki $\mathrm{H}$ and Kleihues P: Epidemiology and etiology of gliomas. Acta Neuropathol 109: 93-108, 2005.

$8 \mathrm{Gu}$ J, Liu Y, Kyritsis AP and Bondy ML: Molecular epidemiology of primary brain tumors. Neurotherapeutics 6(3): 427-435, 2009.

9 Wrensch M, Fisher JL, Schwartzbaum JA, Bondy M, Berger M and Aldape KD: The molecular epidemiology of gliomas in adults. Neurosurg Focus 19(5): E5, 2005.

10 Fischer U and Meese E: Glioblastoma multiforme: the role of DSB repair between genotype and phenotype. Oncogene 26(56): 7809-7815, 2007.

11 Raff M: Cell suicide for beginners. Nature 396: 119-122, 1998.

12 Hajra KM and Liu JR: Apoptosome dysfunction in human cancer. Apoptosis 9(6): 691-704, 2004.

13 Hengartner MO: The biochemistry of apoptosis. Nature 407: 770-776, 2000.

14 Kumar S: Caspase function in programmed cell death. Cell Death Differ 14: 32-43, 2007.

15 Nicholson DW and Thornberry NA: Caspases: killer proteases. Trends Biochem Sci 22: 299-306, 1997.

16 Thornberry NA: The caspase family of cysteine proteases. $\mathrm{Br}$ Med Bull 53: 478-490, 1997.

17 Shiozaki EN, Chai J, Rigotti DJ, Riedl SJ, Li P, Srinivasula SM, Alnemri ES, Fairman R and Shi Y: Mechanism of XIAPmediated inhibition of caspase-9. Mol Cell 11: 519-527, 2003.

18 Bian X, Giordano TD, Lin HJ, Solomon G, Castle VP and Opipari Jr. AW: Chemotherapy-induced apoptosis of S-type neuroblastoma cells requires caspase- 9 and is augmented by CD95/Fas stimulation. J Biol Chem 279: 4663-4669, 2004.

19 https://www.ncbi.nlm.nih.gov/pubmed/?term=caspase +9 +polymorphism

20 Kleihues P and Cavenee WB: In World Health Organization Classification of Tumors: Pathology and Genetics: Tumors of the nervous system. IARC Press: Lyon. 6-7, 2000.

21 Wang YX, Zhao L, Wang XY, Liu CM and Yu SG: Role of Caspase 8, Caspase 9 and $\mathrm{Bcl}-2$ polymorphisms in papillary thyroid carcinoma risk in Han Chinese population. Med Oncol 29(4): 2445-2451, 2012.

22 Theodoropoulos GE, Gazouli M, Vaiopoulou A, Leandrou M, Nikouli S, Vassou E, Kouraklis $G$ and Nikiteas $\mathrm{N}$ : Polymorphisms of caspase 8 and caspase 9 gene and colorectal cancer susceptibility and prognosis. Int J Colorectal Dis 26(9): 1113-1118, 2011.
23 Thompson CB: Apoptosis is the pathogenesis and treatment of disease. Science 267: 1456-1462, 1995.

24 Ter-Minassian M, Zhai R, Asomaning K, Li Su, Zhou W, Liu G, Heist RS, Lynch TJ , Wain JC, Lin X , DeVivo I and Christianiet DC: Apoptosis gene polymorphisms, age, smoking and the risk of non-small cell lung cancer. Carcinogenesis 29(11): 21472152, 2008.

25 Lee SY, Choi YY, Choi JE, Kim MJ, Kim JS, Jung DK, Kang HG, Jeon HS, Lee WK, Jin G, Cha SI, Kim CH, Jung TH and Park JY: Polymorphisms in the caspase genes and the risk of lung cancer. J Thorac Oncol 5(8): 1152-1158, 2010.

26 Hirano A, Nagai H, Harada H, Haga S, Kajiwara T and Emi M: Two novel single-nucleotide polymorphisms of the Caspase-9 (CASP9) gene in the Japanese population. Genes Immun 2: 117118, 2001.

27 Kesarwani P, Mandal RK, Maheshwari R and Mittal RD: Influence of caspases 8 and 9 gene promoter polymorphism on prostate cancer susceptibility and early development of hormone refractory prostate cancer. BJU Int 107(3): 471-476, 2011.

28 Andreoli V, Trecroci F, La Russa A, Valentino P, Condino F, V Latorre, R Nisticò, D Pirritano, Del Giudice F, Canino M, Cittadella R and Quattrone A: CASP-9: A susceptibility locus for multiple sclerosis in Italy. J Neuroimmunol 210: 100-103, 2009.

29 Hosgood HD 3rd, Baris D, Zhang Y, Zhu Y, Zheng T, Yeager M, Welch R, Zahm S, Chanock S, Rothman N and Lan Q: Caspase polymorphisms and genetic susceptibility to multiple myeloma. Hematol Oncol 26(3): 148-151, 2008.

30 Lan Q, Zheng T, Chanock S, Zhang Y, Shen M, Wang SS, Berndt SI, Zahm SH, Holford TR, Leaderer B, Yeager M, Welch $\mathrm{R}$, Hosgood D, Boyle P and Rothman N: Genetic variants in caspase genes and susceptibility to non-Hodgkin lymphoma. Carcinogenesis 28: 823-827, 2007.

31 Zhang ZY, Xuan Y, Jin XY, Tian X and Wu R: CASP-9 gene functional polymorphisms and cancer risk: a large-scale association study plus meta-analysis. Genet Mol Res 12(3): 3070-3078, 2013.

32 Yan S, Li YZ, Zhu XW, Liu CL, Wang P and Liu YL: Role of the CASP-9 Ex5+32 G>A polymorphism in susceptibility to cancer: A meta-analysis. Exp Ther Med 5(1): 175-180, 2013.

$33 \mathrm{Xu} \mathrm{W}$, Jiang S, Xu Y, Chen B, Li Y, Zong F, Zhao W and Wu J: A meta-analysis of caspase 9 polymorphisms in promoter and exon sequence on cancer susceptibility. PLoS One 7(5): e37443, 2012. 